2015

\title{
High Surface Area and Z' in a Thermally Stable 8-fold Polycatenated Hydrogen-bonded Framework
}

\author{
Cassandra A. Zentner \\ Oberlin College \\ Holden W.H. Lai \\ Oberlin College \\ Joshua T. Greenfield \\ Oberlin College \\ Ren A. Wiscons \\ Oberlin College \\ Matthias Zeller \\ Youngstown State University \\ Follow this and additional works at: https://engagedscholarship.csuohio.edu/encbe_facpub \\ Ere next page for additional authors \\ Part of the Chemical Engineering Commons \\ How does access to this work benefit you? Let us know!
}

\section{Repository Citation}

Zentner, Cassandra A.; Lai, Holden W.H.; Greenfield, Joshua T.; Wiscons, Ren A.; Zeller, Matthias; Campana, Charles F.; Talu, Orhan; FitzGerald, Stephen A.; and Rowsell, Jesse L.C., "High Surface Area and Z' in a Thermally Stable 8-fold Polycatenated Hydrogen-bonded Framework" (2015). Chemical \& Biomedical Engineering Faculty Publications. 147.

https://engagedscholarship.csuohio.edu/encbe_facpub/147

This Article is brought to you for free and open access by the Chemical \& Biomedical Engineering Department at EngagedScholarship@CSU. It has been accepted for inclusion in Chemical \& Biomedical Engineering Faculty Publications by an authorized administrator of EngagedScholarship@CSU. For more information, please contact library.es@csuohio.edu. 


\section{Authors}

Cassandra A. Zentner, Holden W.H. Lai, Joshua T. Greenfield, Ren A. Wiscons, Matthias Zeller, Charles F. Campana, Orhan Talu, Stephen A. FitzGerald, and Jesse L.C. Rowsell 


\title{
High surface area and $Z^{\prime}$ in a thermally stable 8-fold polycatenated hydrogen-bonded framework
}

\author{
Cassandra A. Zentner, Holden W. H. Lai, Joshua T. Greenfield, Ren A. Wiscons,a \\ Matthias Zeller, Charles F. Campana, Orhan Talu, Stephen A. FitzGerald and \\ Jesse L. C. Rowsell
}

\begin{abstract}
1,3,5-Tris(4-carboxyphenyl)benzene assembles into an intricate 8 -fold polycatenated assembly of $(6,3)$ hexagonal nets formed through hydrogen bonds and $\pi$-stacking. One polymorph features 56 independent molecules in the asymmetric unit, the largest $Z^{\prime}$ reported to date. The framework is permanently porous, with a BET surface area of $1095 \mathrm{~m}^{2} \mathrm{~g}^{-1}$ and readily adsorbs $\mathrm{N}_{2}, \mathrm{H}_{2}$ and $\mathrm{CO}_{2}$.
\end{abstract}

Microporous materials have potential applications in separation, catalysis, and gas capture. ${ }^{1}$ Among porous materials, molecular crystals are advantageous for their high flexibility during guest sorption, easy purification, characterization and regeneration by recrystallization. However, few examples of porous molecular crystals are known due to their unpredictable crystal structures and tendency to lose crystallinity upon solvent evacuation. ${ }^{2}$ There are two types of porous molecular structures: intrinsic and extrinsic. Intrinsic porosity occurs in solids composed of porous molecular building units, whereas extrinsic porosity arises from interactions between nonporous molecules. As such, examples of the latter category are infrequent and rarely tolerate solvent evacuation. ${ }^{3}$ Paramount to overcoming the challenges in designing extrinsically permanently porous molecular materials is the appropriate choice of the supramolecular synthons. ${ }^{4}$ Hydrogen-bonded organic frameworks (HOFs) feature directional hydrogen bonds that stabilize the framework, such as carboxylic acid dimers that connect in a highly predictable fashion. ${ }^{5}$ HOFs have recently garnered attention for their superior separation capabilities, compared to other porous materials. ${ }^{6}$ These recent reports have demonstrated HOFs' stability and their applications in the selective capture of liquids and gases and separation of enantiomers.

In our studies we investigated the self assembly, thermal stability and porosity of 1,3,5-tris(4-carboxyphenyl)benzene (tcpb, Fig. 1), as well as its potential for gas adsorption. Tcpb (also referred to as $\mathrm{H}_{3} \mathrm{BTB}$ ) has been widely used for the synthesis of metal organic frameworks (MOFs). ${ }^{7}$ MOFs consisting of the deprotonated BTB linker were found to have high surface area and gas adsorption capacity. ${ }^{7 f}$ However, little is known about its self assembly in the solid state and despite numerous attempts, the crystal structure of unsolvated tcpb remained elusive. ${ }^{8,11 a}$ The only fully characterized crystal involving protonated tcpb is a DMF solvate in which the carboxylic acid groups are capped by DMF molecules, preventing the formation of carboxylic acid dimers. ${ }^{9}$ The tcpb molecules instead interact though a six-phenyl embrace. When tcpb is deposited on solid surfaces, a different structural motif has been observed in the form of a $2 \mathrm{D}(6,3)$ honeycomb assembly (Fig. 2). ${ }^{10}$ Examples of the honeycomb motif have also been observed in the structures of two methyl substituted tcpb derivatives with large void space occupied by solvate molecules, but their potential porosity had not been studied. ${ }^{11}$

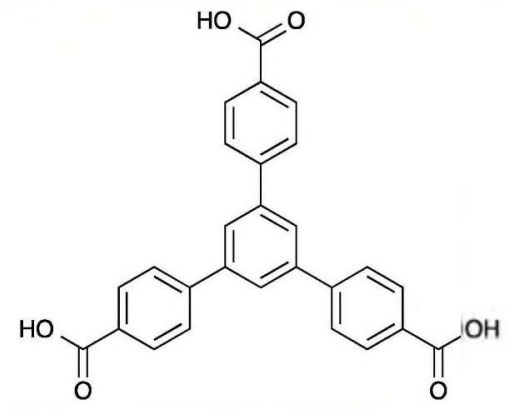

Fig. 1 1,3,5-Tris(4-carboxyphenyl)benzene (tcpb). 


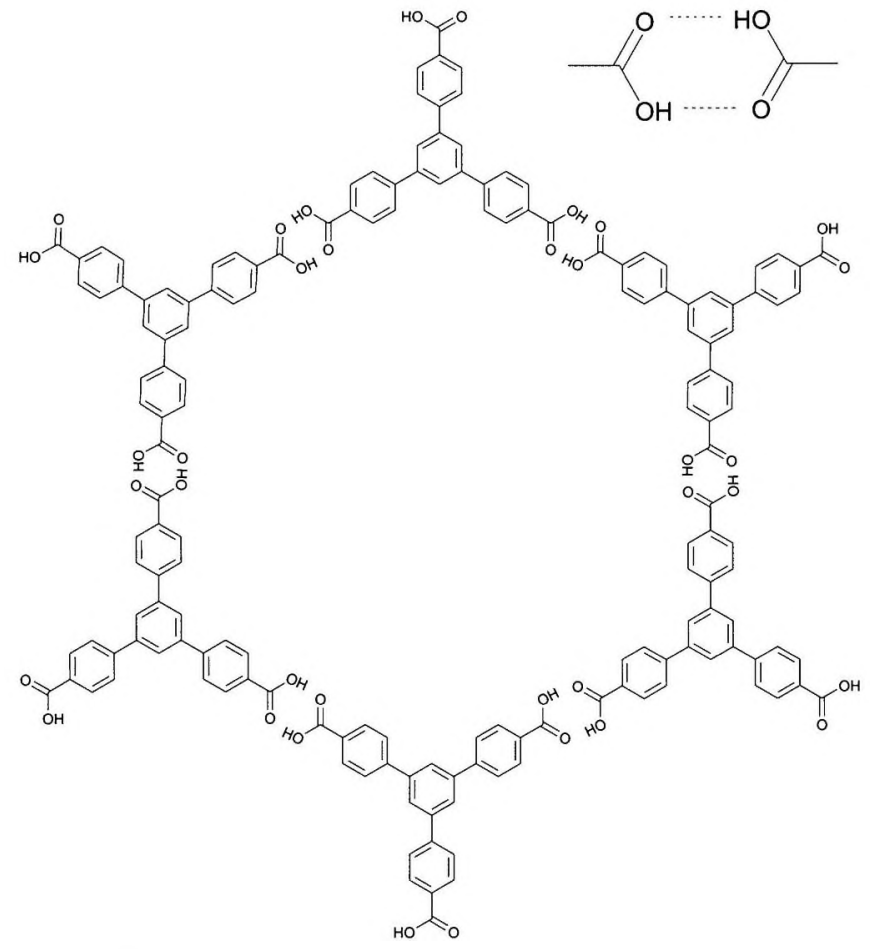

Fig. 2 Formation of hexagonal sheets via carboxylic acid dimer linkages in the $(6,3)$ honeycomb assembly of tcpb molecules.

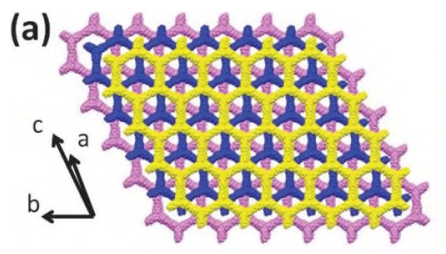

(b)

(c)
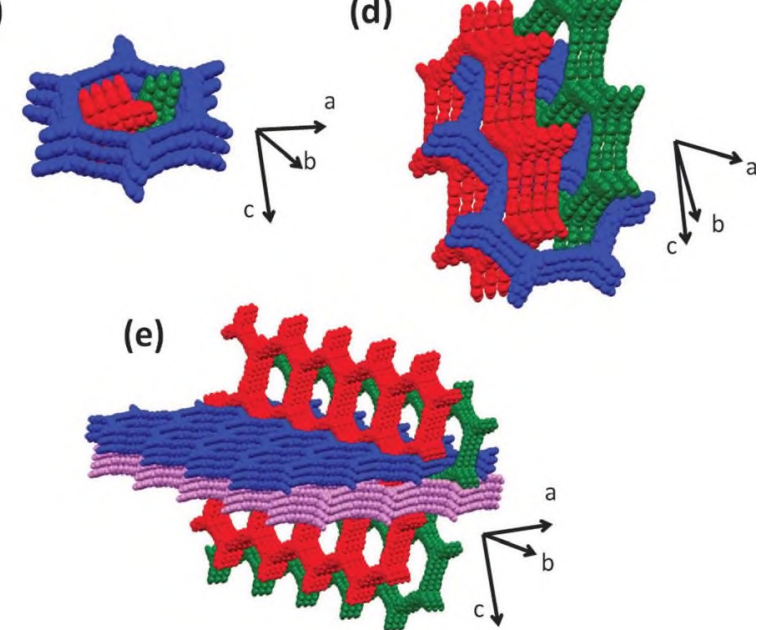

Fig. 3 Crystal structure representations ( $P 1$ polymorph shown). (a) Overhead view of the hexagonal sheets, shifted in respect to each other; (b) $\pi$-stacks of hexagonal sheets with thickness of alternating 3 and 4 molecules; (c) 7 molecules fit within the hexagons; (d) 8-fold polycatenation; (e) extended view of the 8 -fold polycatenation of hexagonal layers.
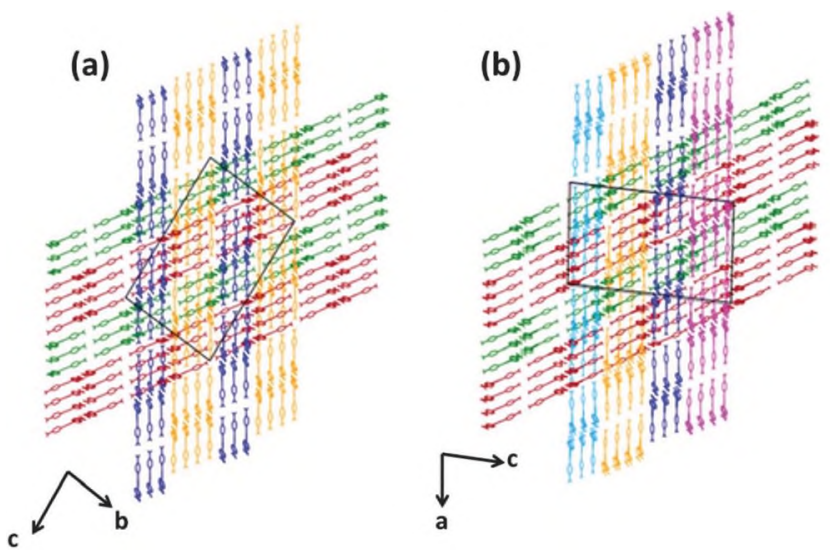

Fig. 4 Stacking in the two polymorphs. (a) 12 polymorph. 3 and 4 stacks in the polycatenated sheets are symmetry equivalent, related by the 2 -fold rotation axis, giving rise to a $A B A B$ stacking; (b) $P 1$ polymorph. 3 and 4 stacks along the $a$-axis are related by translation, with $A B A B$ stacking. Stacks along the $c$-axis are distinct and symmetry independent of each other, leading to an $A B A^{\prime} B^{\prime}$ type stacking

Obtaining structures of tcpb and its derivatives with persistent porosity remains a challenge. Herein, we report an HOF of tcpb that not only assembles in the solid state via a honeycomb motif, but possesses a high porosity and thermal stability rivaling the most advanced examples from MOF chemistry.

We obtained single crystals of tcpb by slow-cooling and evaporation of its solutions in ethanol and various propanols and butanols.§ Colorless to slightly yellow crystals were obtained as beveled prisms with two major shapes: elongated needles and thick plates (Fig. S1, ESI‡) which were assigned by single crystal $\mathrm{X}$-ray diffraction to two distinct polymorphs with space groups $I 2$ and $P 1$, respectively.§

Both polymorphs feature hexagonal $(6,3)$ honeycomb layers formed through carboxylic acid dimers (Fig. 3a). Individual hexagonal sheets assemble in stacks 3 or 4 molecules thick that alternate with parallel stacks shifted with respect to each other (Fig. 3a and b). The hexagons have a diameter of $c a .29 \AA$, ideally sized to accommodate another set of 7 stacked tcpb molecules (Fig. 3c). A second set of hexagonal sheets, with the same 3 plus 4 alternating pattern, intertwines with the first

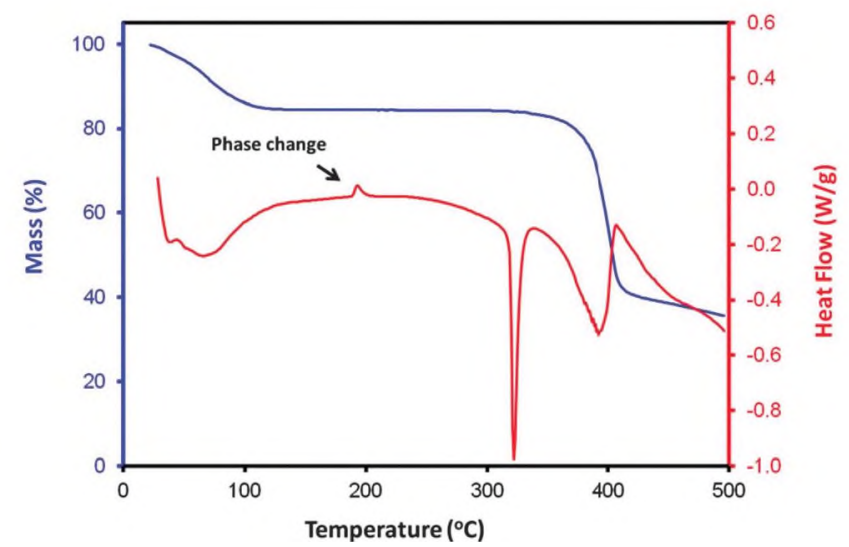

Fig. 5 TGA and DSC under $\mathrm{N}_{2}$. 


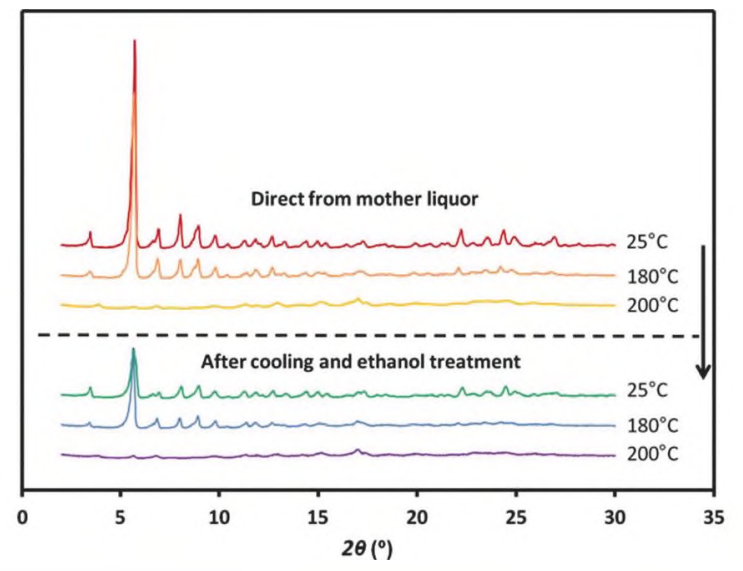

Fig. 6 VT PXRD patterns before and after ethanol treatment, measured under $\mathrm{N}_{2}$. Arrow indicates the sequence of the patterns taken.

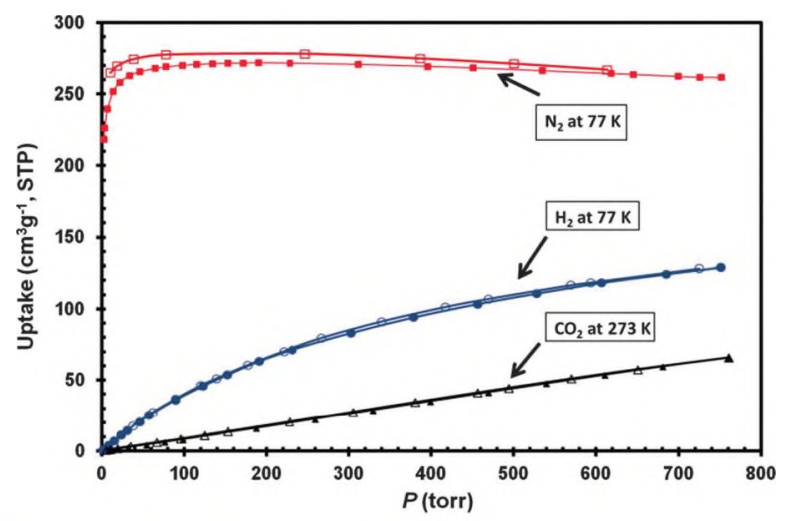

Fig. 7 Adsorption isotherms of $\mathrm{N}_{2}, \mathrm{H}_{2}$ and $\mathrm{CO}_{2}$.

(Fig. 3d and e). Tcpb molecules within the stacks slip and sheets incline with respect to each other at an angle of $c a .68^{\circ}$, forming a polycatenated inclined framework with 8-fold polycatenation. ${ }^{12}$ Similar polycatenation, but displaying only 3 and 6-fold interpenetration, was observed for the methyl derivatives of tcpb. The void space, comprising infinite wavering channels, is $38 \%$ in both polymorphs of tcpb (Fig. S8, ESI ).

Despite sharing these characteristics, the polymorphs differ in their unit cells. The $I 2$ cell has an asymmetric unit containing 14 independent molecules, all having one type of defect propeller conformation (Fig. S2, ESI ). One set of 3 plus 4 layer stacks is symmetry independent, leading to an ABAB type stacking. The polycatenating hexagonal sheets are created through the two-fold rotation axis (Fig. 4a). The asymmetric unit of the $P 1$ polymorph contains a record 56 independent molecules, much higher than the largest currently reported value of $32 .{ }^{13}$
Two types of defect propeller conformations are present in this structure, assembling into six sets of crystallographically independent 3 plus 4 stacks of hexagonal sheets. The first set of hexagonal sheets has the same ABAB pattern as in the $I 2$ structure, stacking along the $a$-axis. The polycatenating set of hexagonal sheets stacking along the $c$-axis features four sets of crystallographically distinct stacks with an $\mathrm{ABA}^{\prime} \mathrm{B}^{\prime} \mathrm{ABA}^{\prime} \mathrm{B}^{\prime}$ repeating pattern (Fig. $4 \mathrm{~b}$ ). A more detailed description of the polymorphs can be found in the ESI.t.

All crystallization procedures yielded a mixture of the two polymorphs, which have indistinguishable void volumes and predicted powder patterns (Fig. S9, ESI $\$$ ). No attempts were made to distinguish between the two forms for the purpose of stability and porosity measurements. Thermogravimetric analysis (TGA) of samples grown from ethanol reveals that all solvent was evacuated when the temperature reached $130{ }^{\circ} \mathrm{C}$, with a mass Ioss of $\sim 15 \%$ (Fig. 5 ). Variable temperature powder X-ray diffraction (VT PXRD) analysis of the same batch of crystals shows that the structure was retained up to $180^{\circ} \mathrm{C}$, much higher than the temperature required for complete solvent evacuation (Fig. 6; see ESI f for other solvent systems). The structure drastically changes around $200{ }^{\circ} \mathrm{C}$, indicated by a loss of intensity in the PXRD pattern, and coinciding with an exotherm in the differential scanning calorimetry (DSC) trace. Variable temperature single crystal analysis shows a sudden unit cell volume reduction of about $10 \%$ around this temperature (Fig. S15 and Table S2, ESI‡). Simple cooling below the $200{ }^{\circ} \mathrm{C}$ phase change temperature does not recreate the original powder patterns. Regeneration was however achieved by soaking the crystals in ethanol. Since tcpb is sparingly soluble in ethanol at room temperature, the crystals do not completely dissolve and recrystallize, rather, ethanol catalyzes the reverse phase transformation.

Void space and thermal stability of the material prompted us to investigate the gas adsorption behavior of tcpb. $\mathrm{N}_{2}$ adsorption isotherms are Type-I, typical for microporous materials (Fig. 7). ${ }^{14}$ Hysteresis is not observed during desorption, indicating a lack of meso- or macro-porosity. The isotherms reach a maximum around $200 \mathrm{Torr}$, indicating that the highest possible value of the surface excess isotherm is reached. $P / P_{0}$ at this pressure is 0.26 , and the BET surface area, calculated following the protocol of Rouquerol is ca. $1095 \mathrm{~m}^{2} \mathrm{~g}^{-1}$ (Table 1$) .{ }^{15}$ This is not only one of the largest reported surface areas for an extrinsically porous molecular structure to date, but it is higher than that of many intrinsically porous molecular materials. ${ }^{3 a, 16}$ The average pore size was determined to be about $18.5 \AA$, and the total pore volume is $c a .0 .42 \mathrm{~cm}^{3} \mathrm{~g}^{-1}$, which is within the range of highly porous solid structures.

The $\mathrm{H}_{2}$ excess adsorption capacity at $77 \mathrm{~K}$ and atmospheric pressure corresponds to $1.14 \%$ by weight, which is remarkable

Table 1 Summary of adsorption results ( $2 \mathrm{nd}$ control measurements in parentheses). Isotherms were measured at atmospheric pressure and $77 \mathrm{~K}\left(\mathrm{~N}_{2}, \mathrm{H}_{2}\right.$ ) or $273 \mathrm{~K}\left(\mathrm{CO}_{2}\right)$

\begin{tabular}{lllllll}
\hline & BET surface area $\left(\mathrm{m}^{2} \mathrm{~g}^{-1}\right)$ & BET pore volume $\left(\mathrm{cm}^{3} \mathrm{~g}^{-1}\right)$ & BET pore size $(\hat{\mathrm{A}})$ & Vol. $\mathrm{N}_{2}\left(\mathrm{~cm}^{3} \mathrm{~g}^{-1}\right)$ & Vol. $_{2}\left(\mathrm{H}^{3} \mathrm{~g}^{-1}\right)$ & Vol. $\mathrm{CO}_{2}\left(\mathrm{~cm}^{3} \mathrm{~g}^{-1}\right)$ \\
\hline Tcpb & $1095(1094)$ & $0.4202(0.4206)$ & $18.51(18.49)$ & $266(262)$ & $129(128)$ & $66(63)$
\end{tabular}


for a material with only $38 \%$ porosity. The limiting isosteric heat of adsorption for $\mathrm{H}_{2}$ at zero coverage is $5.7 \mathrm{~kJ} \mathrm{~mol}^{-1}$. The $\mathrm{H}_{2}$ adsorption values are comparable to other porous organic materials and MOFs without open metal sites. ${ }^{1,2 a} \mathrm{CO}_{2}$ adsorption at RT is within Henry's law range with a limiting isosteric heat of adsorption of $22 \mathrm{~kJ} \mathrm{~mol}^{-1}$, indicative of the much higher quadrupole moment of $\mathrm{CO}_{2}$ compared to $\mathrm{H}_{2}$. See ESI $\ddagger$ for additional data on gas absorption and porosity.

In summary, we have presented a hydrogen-bonded framework with exceptional thermal stability and high surface area unusual for an extrinsically porous molecular compound. Its complicated polycatenation leads to a record 56 independent molecules in the asymmetric unit for one of two polymorphs and contributes to the exceptional strength of the framework. Furthermore, tcpb assembles via predictable hydrogen bonding motifs, helping to further our ability to rationally design thermally robust, porous networks. By functionalizing the tcpb molecule, and using the crystallization techniques presented, it may be possible to obtain stable polycatenated materials with the same advantageous properties but with added functionalities.

The authors acknowledge the support of the NSF (DMR-0922588) for the purchase of the powder X-ray diffractometer at Oberlin College. The X-ray diffractometers at Youngstown State University were funded by the NSF (CHE 0087210, DMR 1337296) and the Ohio Board of Regents (CAP-491).

\section{Notes and references}

$\S$ Typical crystallization setup: $10 \mathrm{~g}$ of tcpb was boiled in $3 \mathrm{~L}$ of absolute ethanol and the solution hot filtered. A yellow precipitate that formed initially was filtered off and the filtrate slowly evaporated (see ESI $\neq$ for complete details and other solvent systems). Single crystal XRD data were collected on Bruker AXS X8 Prospector and APEXII CCD diffractometers and processed using Apex $2 .{ }^{17}$ Structures were solved using ShelXD and refined with SHELXL. ${ }^{18,19}$ All non-hydrogen atoms were refined anisotropically. $\mathrm{H}$ atoms were positioned geometrically. Both structures feature large solvent accessible volumes. The highly disordered content of these voids was corrected for using reverse Fourier transform methods. ${ }^{20}$ Additional details are given in the ESI. $\$$ Crystal data for $I 2$ : monoclinic, colorless needle, $\mathrm{C}_{27} \mathrm{H}_{18} \mathrm{O}_{6} \times$ Solv, $M_{\mathrm{r}}=$ $438.41 \mathrm{~g} \mathrm{~mol}^{-1}, a=31.419(6), b=30.116(6), c=45.320(9) \AA, \beta\left(^{\circ}\right)=$ 90.412(2), $V\left(\mathrm{~A}^{3}\right)=42880(14), Z, Z^{\prime}=56,14$, crystal size $(\mathrm{mm})=1.19 \times$ $0.24 \times 0.06, T=100 \mathrm{~K}, \mu\left(\mathrm{mm}^{-1}\right)=0.07, D_{\mathrm{c}}=0.951 \mathrm{~g} \mathrm{~cm}^{-3}$ (not including disordered solvent), $20_{\max }: 50.484$, Mo K $\alpha(0.71073 \mathrm{~A}), 96106$ refl. collec., 4201 param., $R_{\mathrm{int}}=0.060, R F^{2}>2 \sigma\left(F^{2}\right)=0.053, \mathrm{w} R\left(F^{2}\right)=0.138$, $S=0.90$, no. of meas., indep. and obs. $I>2 \sigma(I)$ refl. $=246101,96106$, 46 684. CCDC 1400566. Crystal data for $P 1$ : triclinic, colorless plate, $\mathrm{C}_{27} \mathrm{H}_{18} \mathrm{O}_{6} \times$ Solv, $M_{\mathrm{r}}=438.41 \mathrm{~g} \mathrm{~mol}^{-1}, a=31.1904(16), b=31.2132(14)$, $c=51.976(3) \AA, \alpha=72.710(4), \beta=77.555(3), \gamma=60.912(3)^{\circ}, V\left(\AA^{3}\right)=$ $42068(4), Z, Z^{\prime}=56,56$, crystal size $(\mathrm{mm})=0.62 \times 0.15 \times 0.08, T=100 \mathrm{~K}$, $\mu\left(\mathrm{mm}^{-1}\right)=0.57, D_{\mathrm{c}}=0.969 \mathrm{~g} \mathrm{~cm}^{-3}$ (not including disordered solvent), $2 \theta_{\max }: 136.788^{\circ}, \mathrm{Cu} \mathrm{K} \alpha(1.54178$ A) 148299 refl. collec., 16805 param., $R F^{2}>2\left(F^{2}\right)=0.069$, $w R\left(F^{2}\right)=0.177, S=0.89$, no. of meas., indep. and obs. $I>2 \sigma(I)$ refl. $=148299,148299,73443$. CCDC 1400565.
1 (a) J. R. Holst and A. I. Cooper, Adv. Mater., 2010, 22, 5212-5216; (b) M. E. Davis, Nature, 2002, 417, 813-821; (c) M. P. Suh, H. J. Park, T. K. Prasad and D.-W. Lim, Chem. Rev., 2012, 112, 782-835; (d) J.-R. Li, J. Sculley and H.-C. Zhou, Chem. Rev., 2012, 112, 869-932.

2 (a) N. B. McKeown, J. Mater. Chem., 2010, 20, 10588-10597; (b) A. I. Cooper, Angew. Chem., Int. Ed., 2012, 51, 7892-7894; (c) J. Tian, P. K. Thallapall and B. P. McGrail, CrystEngComm, 2012, 14, 1909-1919.

3 (a) M. Mastalerz, Chem. - Eur. J., 2012, 18, 10082-10091; (b) J. R. Holst, A. Trewin and A. I. Cooper, Nat. Chem., 2010, 2, 915-920.

4 G. R. Desiraju, J. Am. Chem. Soc., 2013, 135, 9952-9967.

5 (a) J. D. Wuest, Chem. Commun., 2005, 5830-5837; (b) O. Ivasenko and D. F. Perepichka, Chem. Soc. Rev., 2011, 40, 191-206.

6 (a) Y. He, S. Xiang and B. Chen, J. Am. Chem. Soc., 2011, 133, 14570-14573; (b) P. Li, Y. He, Y. Zhao, L. Weng, H. Wang, R. Krishna, H. Wu, W. Zhou, M. O'Keeffe, Y. Han and B. Chen, Angew. Chem., Int. Ed., 2015, 54, 574; (c) X.-Z. Lou, X.-J. Jia, J.-H. Deng, J.-L. Zhong, H.-J. Liu, K.-J. Wang and D.-C. Zhong, J. Am. Chem. Soc., 2013, 135, 11684-11697; (d) P. Li, Y. He, J. Guang, L. Weng, J. C.-G. Zhao, S. Xiang and B. Chen, J. Am. Chem. Soc., 2014, 136, 547-549.

7 (a) S. R. Caskey, A. G. Wong-Foy and A. J. Matzger, Inorg. Chem., 2008, 47, 7751-7756; (b) B. Chen, M. Eddaoudi, S. T. Hyde, M. O'Keeffe and O. M. Yaghi, Science, 2001, 291, 1021-1023; (c) H. Furukawa, M. A. Miller and O. M. Yaghi, J. Mater. Chem., 2007, 17, 3197-3204; (d) S. B. Choi, M. J. Seo, M. Cho, Y. Kim, M. K. Jin, D.-K. Jung, J.-S. Choi, W.-S. Ahn, J. L. C. Rowsell and J. Kim, Cryst. Growth Des., 2007, 7, 2290-2293; (e) H. Furukawa, K. E. Cordova, M. O'Keeffe and O. M. Yaghi, Science, 2013, 341, 1230444; $(f)$ H. Furukawa, N. Ko, Y. B. Go, N. Aratani, S. B. Choi, E. Choi, A. O. Yazaydin, R. Q. Snurr, M. O'Keeffe, J. Kim and O. M. Yaghi, Science, 2010, 329, 424-428.

8 V. Vergadou, G. Pistolis, A. Michaelides, G. Varvounis, M. Siskos, N. Boukos and S. Skoulika, Cryst. Growth Des., 2006, 6, 2486-2492.

9 E. Weber, M. Hecker, E. Koepp, W. Orlia, M. Czugler and I. Csoregh, J. Chem. Soc., Perkin Trans. 2, 1988, 1251-1257.

10 (a) M. Ruben, D. Payer, A. Landa, A. Comisso, C. Gattinoni, N. Lin, J.-P. Collin, J.-P. Sauvage, A. De Vita and K. Kern, J. Am. Chem. Soc., 2006, 128, 15644-15651; (b) F. Silly, $J$. Phys. Chem. $C, 2012,116$, 10029-10032; (c) G. Eder, S. Kloft, N. Martsinovich, K. Mahata, M. Schmittel, W. M. Heckl and M. Lackinger, Langmuir, 2011, 27, 13563-13571, and references therein.

11 (a) A. Bajpai, P. Venugopalan and J. N. Moorthy, Cryst. Growth Des., 2013, 13, 4721-4729; (b) A. Bajpai, P. Venugopalan and J. N. Moorthy, CrystEngComm, 2014, 16, 4853-4860.

12 D. M. Proserpio, Nat. Chem., 2010, 2, 435-436.

13 K. M. Steed and J. W. Steed, Chem. Rev., 2015, 115, 2895-2933.

14 J. Rouquerol, D. Avnir, C. W. Fairbridge, D. H. Everett, J. H. Haynes, N. Pernicone, J. D. F. Ramsay, K. S. W. Sing and K. K. Unger, Pure Appl. Chem., 1994, 66, 1739-1758.

15 J. Rouquerol, P. Llewellyn and F. Rouquerol, Stud. Surf. Sci. Catal., 2007, 160, 49-56.

16 T.-H. Chen, I. Popov, W. Kaveevivitchai, Y.-C. Chuang, Y.-S. Chen, O. Daugulis, A. J. Jacobson and O. S. Miljanic, Nat. Commun., 2014, 5,5131 , and reference therein.

17 Apex2 v2011.2-0, Bruker AXS Inc., Madison, Wisconsin, USA, 2011.

18 G. M. Sheldrick, Acta Crystallogr., Sect. A: Found. Crystallogr., 2008, 64, 112-122.

19 G. M. Sheldrick, SHELXL 2014/7, University of Göttingen, Germany, 2014.

20 P. van der Sluis and A. L. Spek, Acta Crystallogr., Sect. A: Found. Crystallogr., 1990, 46, 194-201. 